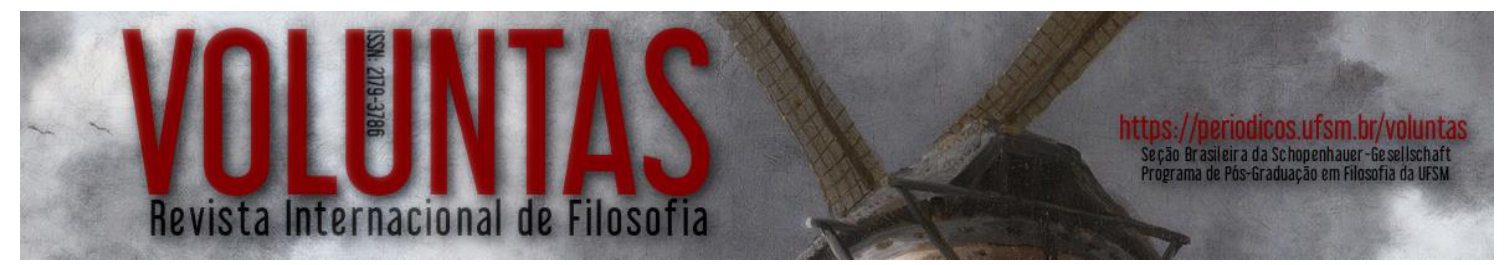

ISSN: 2179-3786

DOI: $10.5902 / 2179378633657$

\title{
Schopenhauer e a sociedade, de Max Horkheimer
}

\author{
Tradução de \\ Thiago Souza Salvio \\ Mestrando pelo Programa de Pós-Graduação em Filosofia da UNESP/Marília. \\ E-mail: thiagosouzasalvio@gmail.com
}

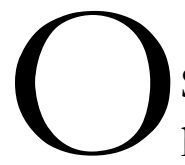

conceito de sociedade burguesa se naturalizou nos tempos de Schopenhauer, mas tinha uma larga pré-história. Com a ruína da ordem hierárquica, acontecida no Renascimento, desapareceu também a certeza de uma articulação natural da humanidade, e a forma das relações sociais exigiu uma justificação; não obstante, o interesse que se anunciava filosoficamente no empurro dos nascentes Estados nacionais enredava, por sua vez, a negação da esfera específica que nós chamamos sociedade: em oposição à grande escolástica, a nova filosofia contrapunha diretamente o Estado à pessoa singular; assim, ainda quando Maquiavel pintou com admirável sagacidade as lutas sociais na Florença, em suas declarações teóricas parece que o governo republicano e o monarca sempre tem que lidar com um conjunto de pessoas singulares: a história fica determinada ao lado do povo e ao lado do governo, não tanto por meio da estrutura dinâmica de agrupamentos condicionados econômica e socialmente quanto - de modo imediato - em virtude de impulsos e paixões de indivíduos. Analogamente pensa Hobbes, tão aparentado a Schopenhauer: com toda sua inteligência das conexões sociais, possui a sua profunda compreensão para os fenômenos e epifenômenos da sociedade - por exemplo, o da ideologia - e a sua comparação do Estado com um organismo, Hobbes entende preferentemente por aqueles indivíduos providos de poder cuja tarefa consistiria na dominação sobre os demais indivíduos; se bem que não seria algo assim como se o Estado se encontrasse "nas" pessoas singulares que, segundo a teoria do contrato estatal, se acham reunidas com fins de segurança e submetidos a um governo: se encontraria simplesmente fora e por cima deles. Se o Estado é republicano, governa vários; se é monárquico tanto em Hobbes como em Maquiavel, melhor se trata da robustez do governo que de sua forma-, coincide com a monarquia. A sentença atribuída a Luís XIV - 'L'Etat c'est moi” - é, mais ou menos o resultado da filosofia estatal de Hobbes.

O pensamento do ser social como algo próprio se aprendeu pela primeira vez na idade contemporânea pelo Iluminismo e domina a oposição entre os philosophes de

Voluntas: Revista Internacional de Filosofia - periodicos.ufsm.br/voluntas - Santa Maria - Vol. 9, n. 2, jul.-dez. 2018, p. 180-189. 
la lumiére e Rousseau. Helvetius explica, seguindo inteiramente a tradição racionalista, que "a pátria são somente os cidadãos e convertê-la em um ser real significa dar ocasião a muitas ideias falsas", Rousseau funda o mito da nação: a pátria deve ser um ente próprio, que penetre todas as pessoas singulares, constituído e renovado perpetuamente pela vontade geral; a totalidade do povo organizado repercute poderosamente sobre os indivíduos singulares como uma energia viva, como uma segunda natureza, não menos sublime e benéfica que a primeira quando não estava mutilada, e por ela, os homens deveriam encontrar de novo o caminho até um nível mais elevado, uma vez que na falaz civilização, na "época da pecaminosidade completa" - para falar com Fichte -, se há desvanecido a pureza dos sentimentos. A desigualdade crassa, o império dos poucos sobre os muitos, aniquilou a ingênua virtude do estado de natureza, que renasce como virtude social, como amor ao ser geral, a pátria que se reconhece com justiça como própria: a sociedade é o núcleo da filosofia rousseauniana. Rousseau se remete - não com toda razão - a Montesquieu: este, em seu estudo comparativo da dependência das instituições nacionais com respeito às condições culturais e naturais, havia defendido, em sentido conservador e estético a tese do papel mediador do clero, a aristocracia e as corporações entre o rei e o povo, e havia convertido a sociedade em objeto de análise; muitos românticos alemães - Hegel também - seguiram Rousseau em sua admiração por Montesquieu, e ordinariamente se reverte o conceito de espírito do povo [Volksgeist] a seu spirit genéral; mas o primeiro de seus contemporâneos que não aplicou a filosofia a sociedade, senão que, ao contrário, desenvolveu a filosofia a partir da ideia de sociedade, foi Rousseau - e após ele Kant, cujos escritos práticos e de filosofia da história subjaz em qualquer lugar a ideia de sociedade justa-. Finalmente, e de modo independente, Saint Simon e Hegel deslindaram a sociedade do Estado para convertê-la em um domínio próprio de investigação: em ambos se considera como uma esfera mediadora, com estrutura e energias próprias, entre o Estado e os indivíduos, assim como esses estão entre si; e cada pessoa singular ficaria determinada por ela não menos que pela natureza e o Estado. Enquanto que com os jovens hegelianos, em especial com Marx, a teoria da sociedade é uma só coisa com a filosofia, em Comte desborda da filosofia (até 1840), em qualidade de ciência particular e depois as demais disciplinas fundamentais, como a última e a suprema destas e deixa por trás um vazio: começa o período positivista da sociologia, assim como o do pensamento em geral.

Quando Schopenhauer fala da vida social se refere mais frequentemente às reuniões de sociabilidade (la compagnie, le monde) da sociedade burguesa em seu conjunto; mas quando se trata desta última, é patente seu parentesco com os ilustrados em sentido próprio, muito maior que com Rousseau ou com os românticos, para não falar de Hegel: como as partículas da matéria estão governadas por leis mecânicas, as relações dos indivíduos o estarão por outras psicológicas; e a sociedade consistirá em manter-se unida em virtude dos mecanismos psicológicos do medo e da agressão - 
aos que a previsão apoia em ocasiões. Posto que, segundo Schopenhauer - e isto se opõe a Helvetius e aos demais -, a educação concerne só ao intelecto, e não ao caráter, é claro que este ser essencial da sociedade não poderia variar: com todos os pensadores que não procuraram entender os lados obscuros da psique humana em conexão com a totalidade social, senão que os hipostasiaram diretamente como traços essenciais, eternos, como situação natural, Schopenhauer acreditou na permanência inacabável e no caráter natural de uma sociedade essencialmente repressiva.

Por muito que a história recente parece confirmar o ceticismo de Schopenhauer, por muito que se tenha destacado na crueldade as consequências das tentativas de mudanças, a apologia da repressão pertence ao mundo que faz necessária a repressão. Ainda que o pessimismo social de Hobbes tivesse um significado ilustrador e progressivo, levou, contudo, a por fim, mediante um Estado forte, as guerras religiosas e civis-, operou desde a época do bom burguês como uma pura reação; o desprezo voltaireano do populacho se refere a massas vítimas do abuso, que contra seus próprios interesses impedem o melhor. Schopenhauer, pelo contrário, não vê a canalha na turba plebeia e aristocrática que encontra diversão nas torturas da praça de Grève e que aplaude cada infâmia, senão nas sublevações de 1848. O mesmo pensamento, a mesma teoria, são outro pensamento e outra teoria em um instante histórico distinto. No século XIX, o enaltecimento de um poder forte do Estado frente aos desejos insaciáveis das massas já não serviu para uma orientação mais racional da jurisdição estatal nem para liberar forças econômicas, senão - na medida crescente - para combater todas as tendências que apontavam para reformas, e procurou boa consciência aos denegadores (isto é verdade na segunda metade do século mais ainda que na primeira). A história da economia não deixa de ter sua parte na ascendente fama de Schopenhauer. Pois o triunfo da técnica e o desenvolvimento da indústria, que se encontram na "interação" - categoria odiada por Schopenhauer com aquela, não proporcionou aos homens a existência mais feliz que se esperava: por pouco que cresceu as diferenças sociais entre 1850 e 1914, tanto mais aumentou sua importância subjetiva e objetiva; as relações se apertaram e o auge levou a uma insegurança ativa, que a Alemanha tem experimentado mais do que nada desde o estabelecimento do Império. (Com efeito, não se saturou como as outras: seu estilo político se funda em haver conseguido a unidade graças a uma vitória militar). Como a agricultura necessita proteção aduaneira, devido a competição exterior, e como a indústria de exportação queria sentir diante si um poderio e necessitava no interior, frente às exigências socialistas, uma mão firme, inclusive os liberais nacionais terminaram por ver a esperança na rápida criação de um Exército, uma Marinha e um Estado forte; a competência internacional conduziu a grandes coalizões, à corrida de armamentos e aos blocos de poder; e o sistema colonial, o lugar ao sol e as crises interiores e exteriores originaram na subconsciência dos povos o desengano e a 
resignação, assim como o sentimento da culpabilidade sobrecarregada, que são característicos da época guilhermina.

A filosofia pessimista se converteu na racionalização do inquietante estado da realidade; ajudou a dispor sobre a essência do mundo a carência de alívios que se haviam esperado do progresso técnico, no lugar de deduzir as desgraças que se anunciavam de uma organização da sociedade na qual a técnica escapou das mãos dos homens. O quietismo filosófico e o templo fin de siècle se enquadravam perfeitamente. Em oposição à confiança na razão e na perfectibilidade dos homens que os tinham ilustrado, com os quais Schopenhauer compartilhava a imagem atomista da sociedade, ele insistia na insensatez dos esforços históricos, já foram teoria ou práxis, palavra ou ato; e do mesmo modo que em sua recusa da filosofia da história se continha o desprezo - sem dúvida muito fundado - pelos movimentos históricos, em especial pelos mais famosos, por outro lado, na proclamação de tal insensatez se descobria a consagração do existente. Todavia, na ausência de uma teoria vigente da sociedade e, antes de tudo, sobre o pressuposto da falta de importância prática de todos os frutos daquele ócio criador por meio do qual Schopenhauer reclamava a tranquilidade e a ordem, é difícil de compreender o interesse de um filósofo independente pela manutenção do estado de coisas tem que haver mais peso filosófico que o interesse dos trabalhadores auxiliares por sua modificação: no rigor lógico, o pessimismo filosófico ou se compadece melhor com a argumentação racional em favor do status quo do que com a propaganda pela subversão. Por outro lado, o mantimento e a perduração de uma ordem não deixa a este, sem mais, inalterado: a mesma sociedade que Schopenhauer queria a salvo de alterações se converteu finalmente em outra seguindo suas próprias leis imanentes, seu próprio conceito; e sua mesma defesa, tão eficaz contribuiu para acabar com a tranquilidade e invocar outra vez na Europa os grandes tempos, ante os quais a filosofia se encontrou sempre em retirada.

Mas no intransigente nominalismo de Schopenhauer frente a sociedade estriba a raiz de sua grandeza. Do mesmo modo que na natureza os gêneros são meras abstrações, diz: "No gênero humano só os indivíduos e o curso de suas vidas são reais; e os povos e suas vidas, meras abstrações"; não tributou nenhum entusiasmo ao mito rousseauniano: nega a existência do coletivo e se aferra aos seres vivos singulares, ao homem e ao animal com suas necessidades e suas paixões, seu agitar-se por existir e pelo bem-estar, sua miséria. Quando apresenta sua doutrina só se faz notar perfeitamente que descreve a Vontade dita como cega e irrealizável, mas não tanto que tenha mensurado com semelhante menção não só o universo, ademais, a ordem inteligível. Também Kant vê, com Rousseau, que no caminho da civilização a prosperidade do indivíduo não melhorou compassadamente e que não parece a meta da história; mas ele e seus sucessores - para não dizer nada da filosofia universitária justificaram a história, apesar de tudo, e inclusive fizeram desta justificação a tarefa de amplas construções. Defronte isto, a filosofia de Schopenhauer - e não meramente 
em sua parte prática, senão precisamente na teórica - poupou à realidade o tributo de ser recoberta no dourado da eternidade: seu rechaço da subversão não está motivado filosoficamente - nem pelo imperativo categórico, nem pelo espírito objetivo, nem por algum sentido oculto -, senão abertamente, pela liberdade da qual participava por seu pecúlio e suas rendas; o medo de ficar exposto a realidade social sem bens, não menos que seus agradecimentos aos defensores da ordem, que ele temia, não ditam nenhum juízo amistoso àquela. Em Schopenhauer, se fizeram filosóficos os sentidos do comerciante, que herdara de seu pai; a naturalidade, que se devia ao dom de encontrar-se a gosto inclusive em outros países e línguas, e a sobriedade em que estava conformado. Atrás do pessimismo, que se deixou explorar ideologicamente na época guilhermina, e atrás do desdém pelo sistema adequado aos tempos e todos os setores, se encontra o impávido interesse pelo destino, aqui e mais além, da pessoa singular. A filosofia há de prestar contas; e como o balanço é negativo, o santo resta ao fim com a razão: quem pretende consertar o mundo se engana. $O$ existente não fica glorificado pela desconfiança schopenhaueriana ante a reforma e a revolução.

A discrição do comerciante organiza até as peças mais íntimas da doutrina: a estética transcendental cobra uma importância em O Mundo como Vontade e Representação porque expõe a subjetividade do princípio de individuação; como o espaço e o tempo não corresponde às coisas em si, a multiplicidade de homens e de coisas mostra ser uma aparência; e a solicitude pelo próprio bem-estar à custa dos demais, uma inversão errônea: o afortunado neste mundo se considera rico em ilusões; a doutrina da idealidade da pura aparência ou fenômeno corrige um cálculo interrompido: que alguém lastime a humanidade em virtude de seu desejo de riquezas e de poderio não o macula tanto como pecador quanto como ludibriado, pois o que consegue é propriamente nada. A filosofia existe para que nada se deixe fraudar. A obra de Schopenhauer está toda penetrada por este instinto e chegou até Nietzsche sem debilitar-se por seus sucessores.

Os traços do burguês ilustrado do século XVIII aparecem no estilo, reflexivo e perfeitamente desenvolvido, e em muitas particularidades, todavia, de modo mais saliente na concepção do todo. Nenhum solene gesto linguístico para sacar da manga um sentido da falta um sentido da falta de sentido e da morte, nenhuma teologia do nada, nenhum substituto da filosofia da história por meio de uma historicização do ser em que as vítimas não apareçam e os verdugos se escondam, pode se confundir com o claro tom da filosofia schopenhaueriana: por muito que esta sustenta como tese principal a inevitabilidade do padecer e da baixeza e sublinhe a inutilidade do protesto, seu estilo constitui um protesto único contra o que seja assim; a crueldade não se converte em um ídolo, e sua interpretação positiva lhe é abominável. Se a intransigência com o círculo eterno da desgraça se entende como uma vingança sublimada, Schopenhauer era um filósofo vingativo; certamente, ele vê o negativo através do medo do ocaso histórico de sua própria forma de existência social - os 
cidadãos de seu gênero desaparecem -; mas se na literatura emancipatória de uma camada social particular, em seu otimismo, pode anunciar-se a chegada, ao mesmo tempo, de seu interesse geral pela passagem a algo maior, o mesmo ocorreria na filosofia de seu ocaso, em seu pessimismo, com o interesse pelo que nele é chamado de progresso, há de se custodiar. O esquema em branco e preto de ascensão e decadência é, desde muito, insuficiente para a evolução social dos fenômenos culturais.

Quando Schopenhauer informa sobre questões históricas - guerra, cruzadas, inquisição - parece estar falando Voltaire, que abrigava para ele, como Goethe e Nietzsche, a máxima veneração. E com Voltaire não tem só em comum a energia com que rechaça o livre-arbítrio e a teodiceia, porém, antes de tudo, a defesa da religião por razões pragmáticas e enquanto ética popular. Indubitavelmente, Schopenhauer quando chega a este assunto - acaba com a verdade da crença em Deus de um modo incomparavelmente mais radical que o decidido teísta francês, cuja crítica não se refere à religião, mas ao fanatismo; ambos se agarram a filosofia em vez da revelação, contudo Schopenhauer busca uma informação sobre a essência do mundo, sobre o "aquém de" e o "além de", e não quer, de modo algum, se dar conta de equivocarse: para ele a pessoa particular, a pergunta pelo destino da alma, pela morte e o pecado original, são mais graves que para o literato militante, a quem preocupa muito uma ordem mais justa deste lado de cá. Mas o que Schopenhauer pusera em jogo precisamente na metafísica a mesma inteligência aguda que os ilustrados na crítica terrena, que cravou os olhos nas coisas últimas e se dedicou inteiramente a elas, o mesmo mediante um método penetrante e lógico - pensa-se unicamente no raciocínio por analogia em virtude do qual estendeu a observação do sentido interno ao fundamento do sistema - que com uma cultivada experiência psicológica, livre do medo dos empregados e do alcance comparável ao dos grandes novelistas, assim como a reunião de profundidade e de naturalidade comercial, fizeram de sua obra expressão de uma constelação única e uma chave da história da filosofia.

Do mesmo modo que no obscuro aspecto do mundo em Schopenhauer se desenha o outro contra sua vontade, ao se aferrar à sociedade perversa revela uma melhor. Desde logo, em muitos lugares a paixão do pensamento passa por cima do veredito do pessimismo social: já no primeiro tomo de O Mundo como Vontade e Representação surge a ideia do "país de Cocanha", que poderia ser realizada em um Estado ilustrado com uma ordem verdadeiramente harmônica; se bem é certo que se acumulam as razões pelas quais, contudo, não é possível: o fato de que se tenha permanecido tão longe desta meta, a inútil ociosidade e o tédio que se dariam, os pequenos negócios particulares e, finalmente, a guerra e o excesso de população. No segundo tomo dos Parerga se formula com maior decisão a ideia do bem social: "Se o ser maquinal continua seus progressos na mesma medida durante mais algum tempo, pode sair daí que as fadigas das forças humanas se evitem quase totalmente, a 
maneira como em grande parte ocorre já com a força do cavalo. Assim, pois, cabe sem dúvida, pensar em certa generalidade da cultura espiritual do gênero humano, o qual, pelo contrário, até o presente tem sido impossível, já que a parte mais numerosa do mesmo tem que dedicar-se a um duro trabalho corporal - pois a irritabilidade e a sensibilidade se encontram sempre e em qualquer lugar em antagonismo, em geral como no caso singular: justamente porque sob ambas se acha, subjacente, uma e a mesma força vital -. Posto que, ademais, artes molliunt mores, acaso desapareçam inteiramente do mundo a guerra em macro e as pendências e duelos em micro, de igual maneira que fizeram agora muito mais infrequentes. Mas não tenho aqui o propósito de escrever uma utopia”. O que não era deliberado cumpre diagnósticos negativos ainda mais a fundo que as digressões no positivo: à maneira daqueles amargos e humanos conhecimentos se confirmam na história mais recente sobrepujando inclusive o pressentimento dos infortúnios que, como se diz no citado \62 de O Mundo como Vontade e Representação, "atualmente só é capaz de representar uma imaginação ousada": não é necessário pensar unicamente no que o fanatismo, as persecuções inacabáveis, os desterros cruéis e extermínios de grupos inteiros, nacionais e religiosos que Filatetes descreve no diálogo sobre a religião, encontraram uma continuação gigantesca no século de Hitler e Stalin; basta recordar a vida social cotidiana nos países que se conduz com mais êxito a luta contra a pobreza. Se conseguiu uma infinidade de coisas: não somente se conjuram uma e outra vez as crises econômicas, mas também das instituições de liberdade; quase se realizou o panorama utópico de Schopenhauer, mas a pressão não se debilitou; não obstante o inimaginável aumento das forças produtivas, a vida não se aliviou com o com o desafogo progressivo; e não só está a espreita dentro e fora, como uma ameaça, uma miséria recorrente - que, desde logo, continua existindo ainda no meio da civilização (em regiões como o sul da Itália vem ao lume de modo mais crasso)-, senão que a melhoria proporcionou novas cargas, umas ideais e outras reais.

Seria fácil fazer o presente falar no sentido de Schopenhauer. Os homens se multiplicam velozmente, e as necessidades ligadas a técnica, mais ainda desde 1900, ao mesmo tempo se multiplicaram por mil os tipos especiais de aparatos novos que o homem tem que adquirir na rua, em parte por causa de sua profissão e em parte por causa do imprescindível prestígio. É inegável o efeito civilizatório de semelhante adoção: a eliminação progressiva da servidão doméstica da mulher, a equivalência das maneiras de ser do trabalhador e do empresário, a democratização da existência; e a civilização não é algo assim como o oposto a cultura, segundo queriam os agentes do terceiro Reich, porém, seu pressuposto. Mas, sem dúvida alguma, também é inegável o deslocamento - que se impõe de modo forçoso - das energias econômicas a favor do instrumental: a compra do veículo e do receptor se faz inevitável e obrigação, a fundação de uma biblioteca privada séria passa a ser um luxo mais raro - e, ademais, menos vantajoso, pois o rádio e a imprensa se interam do resumo e das consequências 
do livro, e as matizes contariam só para o especialista -. Este mesmo deslocamento ocasiona, por demasiado, que o efeito benéfico da redução do tempo de trabalho possa se transmutar no excedente de ócio somente na medida limitada: antes que os diferentes instrumentos de entretenimento de massas tenham de combater o tédio do tempo livre - que se encurta por causa da repetitiva ida e volta ao trabalho - nos espera a manutenção do apartamento e dos aparelhos, que mesmo o trabalhador bem assalariado há de cuidar por si, devido ao crescente custo do trabalho manual e de reparos. A mulher exerce uma profissão. O pagamento a prazo de aparelhos cada vez mais confortáveis se prolonga até que, por acaso, estes já são antiquados e serão substituídos por outros ainda mais confortáveis. Se trata de ir ao compasso das obrigações que o desafogo impõe sobre cada um; mas a energia psíquica de que dispõe o indivíduo para os interesses pessoais está limitado por natureza; e o enorme gasto interior que a vida da totalidade - que se reproduz sem coação exterior - exige dos indivíduos a tensa atenção das tarefas, assim como nas diversões - transmitidas mecanicamente - consome muito deles. Talvez Helvetius não estava equivocado ao vincular com uma cultura justa, como fundamento da fantasia, o tédio, que Schopenhauer considera só uma calamidade e o que faz maximamente responsável pelas superstições. A fronteira entre ócio e tédio é borrada, e os homens não alcança ambos; na civilização técnica estão curados tão radicalmente de sua torpeza que desaprendem a resistência; mas esta é a alma da filosofia schopenhaueriana.

Sua ideia de compensação do progresso mediante novas penas, em cujo cumprimento se imporia a representação de algo melhor, encontraria no presente um rico material fenomênico, inclusive se se considera somente aos países do Oeste e se fecha ante a penúria e o terror do Leste. Schopenhauer, que falava com burlas do fumar e dos jogos infantis que não requerem nenhum esforço intelectual da gente, poderia indicar furiosamente a cultura de massas de hoje e seus anúncios, que teriam encontrado com ele o lugar merecido; mas na crítica negativa da situação atual, em que o estrutural adquiriu um poder tão grande, teria que proceder reconhecendo que a força e a intenção da pessoa singular, que se integram no todo, não estão menos determinadas por estes que por aqueles; a totalidade das relações sociais se constitui em cada caso como uma realidade com sua legalidade própria, e é a sociedade, que se origina e muda a partir dos indivíduos - vinculados socialmente -, e não o indivíduo pensado como isolado da sociedade, que oferece cuidado e amparo em distribuição e graus determinados por ela; os indivíduos e grupos, que atuam de modo diverso de acordo com sua posição na sociedade, que cumprem uma função que resulta do jogo de forças da totalidade, não se apoiam em afetos e ideias independentes das instituições decisivas com respeito a justiça e a injustiça. O conjunto total, em que, indubitavelmente, também se incorpora e se desfaz trabalhando o livre e independente diante a sociedade, dá lugar a cultura e a cultura de massas, de seu estado depende o estado da linguagem e, verdadeiramente, o de todos os domínios 
espirituais, provoca o crescimento da técnica como desenvolvimento de um órgão para perceber e levar estes mais longe, assim como uma expectativa maior de vida e a produção necessária de máquinas e de bens de consumo como a força irracional dos mesmos; e os homens engendram o sobre-humano ser social, que não seria capaz de nada sem sua atividade e frente de suas vontades, cujo vigor se logra somente graças às forças daqueles e que, portanto, repercute e atua por sua vez sobre todos os indivíduos.

Em tão escassa medida como as leis psicológicas são derivadas das sociológicas - tais intentos - só desembocam em superficialidades - são estas consequências daquelas: o jogo combinado de umas e outras é, como o de indivíduo e sociedade, diferente em cada época, e para cada momento histórico, pois inclusive os mecanismos psíquicos de todos os indivíduos tomados isoladamente foram os mesmos, funcionariam diversamente em totalidades diferentes em cada caso. Toda solução geral, e também a pessimista, é abstrata, e não em última instância, porque a práxis depende simplesmente da verdade senão que esta depende assim mesmo da ação dos homens; isto é o que quer dizer a doutrina kantiana do primado da razão prática, e o psicologismo resiste tampouco atrás de sua herança - que conservou em qualquer lugar a filosofia de Schopenhauer - como o universalismo social de qualquer tipo.

\section{Referências bibliográficas}

HORKHEIMER, M. Vorträge und Aufzeichnungen, 1949-1973. S. Fischer, 1985.

HORKHEIMER, M.; CRONAN, T. (2004). Schopenhauer and Society (1955). Qui Parle, 15(1), 85-96.

HORKHEIMER, M. Vorträge und Aufzeichnungen, 1949-1973. S. Fischer, 1985.

SCHOPENHAUER, A. Sämtliche Werke. Wiesbaden, 1949.

\section{Agradecimento}

Agradeço a Alexander Jabkowski, à Schopenhauers-Forschungsstelle, Philosophisches Seminar der Johannes Gutenberg Universitaet Mainz. (Departamento de Pesquisa Schopenhauer, Seminário Filosófico da Universidade Johannes Gutenberg Mainz), bem como à mencionada Universidade, pela oportunidade da presente tradução. 
189 | Schopenhauer e a sociedade, de Max Horkheimer

Recebido: 14/07/18

Received: 07/14/18

Aprovado: 06/11/18

Approved: 11/06/18 